\title{
ФОРМИРОВАНИЕ ПРАВОВЫХ ТРАДИЦИЙ В КНР КАК РЕЗУЛЬТАТ ПОСЛЕДОВАТЕЛЬНОЙ ПРАВОВОЙ ДЕЯТЕЛЬНОСТИ
}

Аннотация: Стабильное право является одной из основных иенностей социального государства. Его создание невозможно без формирование правовых стереотипов, традиций и обычаев. На основе опыта КНР в регулировании международных частных отномений были определены способы формирования правовых традиций, особенности последовательной правовой деятельности. Законодательство Китая было выбрано из-за того, что его общество характеризуется традииионализмом, который находит свое отражение и в праве. В этой связи опыт Китая заслуживает пристального внимания. В исследовании в качестве основных общенаучных методов использовались: анализ, синтез, индукция, логический; в качестве специально-юридических: формально-юридический, толкования. Также использовался ичивилизационный подход к изучению объекта исследования. Интерес к зарубежному опыту обусловливается также тем, что в отечественной науке вопросы формирования правовых традиций не нашли достаточного освещения. Очевидно, что на протяжении времени получения опыта, в результате которого может быть сформирован соответствующая правовая традиция, правовая деятельность должна быть последовательно направлена на ее формирование. Правовые традиции могут быть сформированы следующими способами: «от юридической практики к норме права», «от лаконичной нормы права к развернутой через юридическую практику». При этом последовательность правовой деятельности многогранна.

Abstract: Stability of law is one of the main values of the social state. Its formation is impossible, unless legal stereotypes, traditions and customs are formed. Based upon the experience of the PRC in the sphere of regulation of international private law relations the author defines the means of formation of legal traditions and specific features of consecutive legal activities. Chinese legislation was chosen for the analysis since Chinese society is very traditional, which is reflected in its law. That is why, the experience of China deserves special attention. The study involved general scientific methods of analysis, synthesis, induction, logic, and special legal methods: formal legal method and interpretation. The author also used civilization approach towards the object of studies. The interest to the foreign experience is due to the fact that the issues of formation of legal traditions are not sufficiently studied in the Russian science. It is obvious that in the period of gaining experience, which may serve as the basis for the legal tradition, the legal activity should be consecutively aimed at its formation. The legal traditions may be formed via the following means: "from the legal practice to the norm of law", "from a laconic form of law to a detailed legal practice". At the same time consecutive character of legal activity is multi-faceted.

Ключевые слова: Правовые традиции, правовые стереотипы, стабильное право, последовательность правовой деятельности, правовой опыт, формирование правовых традиций, законодательство КНР, традиционализм китайского общества, менталитет, идентичность общества.

Keywords: Legal traditions, legal stereotypes, sustainable law, consecutive legal activity, legal experience, formation of legal traditions, legislation of the PRC, traditionalism of the Chinese society, mentality, identity of the society.

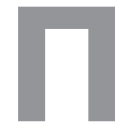

равовые традиции как элементы социального наследия особенностей регулирования общественных отношений являются признаками стабильного права - одной из ценностей социального государства. От их существования зависит предсказуемость изменения, реализации правовых норм, а следовательно, наличие чувства правовой безопасности в обществе. В этой связи для России представляет интерес правовой опыт Китайской Народной Республики, поскольку китайцы имеют 


\section{Право и политика $8(176) \cdot 2014$}

тысячелетний опыт формирования традиций и следования им. И этот опыт не может не найти отражение в ее праве. Это обусловлено тем, что в китайском миропонимании особая роль отводится ритуалу, который представляет собой методологию заданного действия. В ритуале древние китайцы всегда усматривали государственный приоритет, порядок жизни, общепринятые правила и нормы. Конфуций считал, что человек должен чтить традиционные нормы и ритуалы и свои поступки совершать в соответствие с ними для того, чтобы быть достойным членом своего общества. По этому поводу он говорил: «Благородный муж усердно изучает литературу, сдерживает свой нрав правилами ритуала и вряд ли уклонится с пути» ${ }^{1}$. В этом высказывании Конфуция кроется глубокий смысл, который заключается в том, что если следовать установленным правилам, то действия будут соответствовать признанным в обществе нормам. Следование таким правилам привело к тому, что традиции, стереотипы мышления и поведения Древнего Китая до сих пор находят своё отражение в правовых ценностях современных китайцев. Такой традиционализм китайского общества находит отражение и в правовой системе КНР.

Целью настоящей работы является определение способов формирования правовых традиций в регулирование международных частных отношений на примере института применения коллизионных норм и норм иностранного права. Выбор этого института обусловлен тем, что в Китайской Народной Республике с момента ее образования до начала 80 -х годов XX в. международное частное право не существовало. Все отношения с участием иностранцев на территории КНР в указанный период регулировались только китайским правом. В связи с этим обращает внимание первый правовой нормативный акт, закрепивший нормы международного частного права: Основные принципы гражданского законодательства КНР от 12 апреля 1986 г. ${ }^{2}$ (далее - Основные принципы). Его особенностью является его неизменность на протяжении почти 25 лет вплоть до вступления в силу в 2011 г. Закона Китайской Народной Республики о выборе права к гражданским отношениям с иностранным элементом от 28 октября

\footnotetext{
${ }^{1}$ Конфуций. Лунь юй / Конфуций // Confucius Pablishing Co. Ltd. URL: http://www.confucius.org/lunyu/rd0413.htm (дата обращения 20.03.2014).

${ }^{2}$ General Principles of the Civil Law of the People's Republic of China of 12 April 1986. URL: www.lawinfochina.com (дата обращения 15.06.2014).
}

2010 г. ${ }^{3}$ (далее - Закон от 28 октября 2010 г.). Несмотря на отсутствие поправок к Основным принципам с 1986 г. до 2011 г., можно говорить о том, что в современном Китае сложились собственные традиции в области регулирования международных частных отношений, которые нашли отражение в Законе от 28 октября 2010 г. Доказательством этого может служить анализ формирования правовых традиций на примере института применения иностранного права, основные норм которого определяют порядок первичной квалификации, отношение к обратной отсылке, применение права стран с множественностью правовых систем, ограничение применения норм иностранного права.

Проблема первичной квалификации фактических правоотношений с иностранным элементом и терминов, соответствующих ему коллизионных норм, в законодательстве КНР до принятия Закона от 28 октября 2010 г. не имела разрешения. Тем не менее, необходимо отметить, что в пункте 2 статьи 146 Основных принципов, устанавливающей порядок возмещения вреда, было закреплено правило квалификации противоправного действия на территории иностранного государства. В ней было определено, что действие не считалось правонарушением, если оно совершалось вне пределов территории и не рассматривалось правом КНР как противоправное. Таким образом эта норма определяла право КНР как применимое при определении на её территории понятия «правонарушение» и квалификацию фактически возникших отношений в качестве правонарушения.

С начала становления международного частного права в Китае в доктринальной литературе высказывалось несколько точек зрения в отношении возможного способа разрешения проблемы первичной квалификации в этой стране. Большинство исследователей придерживались мнения, что первичная квалификация должна осуществляться в соответствии с Lex fori (закон суда) в субсидиарном порядке - иными правилами; другие считали, что на территории КНР первичная квалификация могла бы быть осуществлена в соответствии с правом КНР или применимым к правоотношению правом ${ }^{4}$.

На практике в условиях отсутствия норм, устанавливающих правила, на основе которых должна была быть осуществлена первичная квалификация,

\footnotetext{
${ }^{3}$ Law of the People's Republic of China on Choice of Law for Foreignrelated Civil Relationships of 28 October 2010. URL: www.lawinfochina.com (дата обращения 15.06.2014).

${ }^{4}$ Wang Hui. A review of China's private international law during the 30 year period of reform and opening up // Asian Law Institute Working Paper. - № 2. - May 2009. - P.3.
} 
китайские судьи исходили из понятий, имеющих место в праве КНР $\mathrm{K}^{5}$ В соответствии с такой сложившейся практикой Закон от 28 октября 2010 г. в ст. 8 закрепил правило, что природа гражданских отношений с иностранным элементом должна определяться Lex fori, то есть по праву суда без каких-либо исключений.

На основании вышеизложенного можно констатировать, что, несмотря на то, что Закон от 28 октября 2010 г. впервые закрепил институт первичной квалификации, он закрепил уже сложившуюся практику, несмотря на различные доктринальные точки зрения. Такая практика возникла под влиянием экономических, политических и социальных преобразований в обществе и была обусловлена необходимостью регулирования отношений с участием иностранцев на территории Китая. Сложившаяся практика китайских судов рациональна. Она, во-первых, облегчала труд судей при квалификации отношений с иностранным элементом и подборе соответствующей коллизионной нормы для определения применимого права, во-вторых, обеспечивала эффективность правовых действий на начальном этапе разрешения споров. Ее целесообразность объясняется также и тем, что до судебной реформы, которая началась в 90-х годах, судьи назначались с учетом их лояльности к партии и правительству, и не все из них имели высшее юридическое образование. Кроме того, в Китае отсутствовала правоприменительная практика разрешения споров с иностранным элементом.

Закрепление в норме закона правил, сформированных в ходе осуществления относительно длинной правоприменительной практики (около 25 лет), а не в период возникновения необходимости в них, дает основание полагать, что правоприменительная традиция реализации рассматриваемых норм сложилась. Зафиксированный в нормах права опыт деятельности судебных органов, состав которых качественно был обновлен в ходе судебных реформ с начала 90-х годов $\mathrm{XX}$ в. представителями нового поколения, не дает основания ожидать изменения соответствующих норм Закона от 28 октября 2010 г. в ближайшем будущем.

\footnotetext{
${ }^{5}$ Huang Jin and Du Huanfang. Chinese judicial practice in Private in 2001 // Chinese Journal of International Law. - 2003. - № 2(1). C.387 - 416; Huang Jin and Du Huanfang. Chinese judicial practice in Private in 2002 // Chinese Journal of International Law. - 2005. - № 4 (2). - C.647 - 676. Huang Jin and Du Huanfang. Chinese judicial practice in Private international law: 2003 // Chinese Journal of International Law. - 2008. - Vol.7. - № 1. URL: http://chinesejil. oxfordjournals; Private international law in the Chinese judicial practice in 2006. URL: http://www.iolaw.org.cn/pdf/paper/2010/Chinese $\% 20$ Judicial\%20Practice\%20in \%20Privat\%20International\%20Law\%202006.pdf (дата обращения 15.06.2014).
}

При разрешении споров с иностранным элементом правоприменители всех государств рано или поздно сталкиваются с проблемой обратной отсылки. Ее разрешение заключается в ответе на вопрос: в случае определения применимого права иностранного государства применяются материальные или коллизионные нормы его законодательства? Несмотря на то, что в Основных принципах не была решена проблема обратной отсылки, нельзя полностью согласиться с тем, что Китай являлся страной, «законы которой вообее не решали эту проблему» ${ }^{6}$. Действительно законы КНР не решали рассматриваемую проблему, но она в отношение определения применимого права к гражданским, коммерческим договорам была решена Верховным Народным Судом КНР 7 , сформулировавшим правовую норму. Такая норма была закреплена, например, в п. 5 ст. 2 изданных в 1987 г. Верховным Народным Судом КНР Комментариях к некоторым вопросам применения Закона КНР о применении иностранного права об экономических контрактах ${ }^{8}$. Согласно ей в случае выбора закона, подлежащего применению при разрешении споров по договорам на основе принципа наиболее тесной связи с правом какого-либо государства, применяется материальное, а не коллизионное право. В соответствие с Правилами Верховного Народного Суда КНР по существенным вопросам, касающимся применения права при рассмотрении договорных споров с иностранным элементом по гражданским и коммерческим вопросам от 23 июля 2007 г. ${ }^{9}$ (далее - Правила Верховного Народного Суда КНР от 23 июля 2007 г.), коллизионное право КНР отсылало к материальному праву иностранного государства, а не коллизионному и процессуальному (ст. 1).

Исходя из смысла документов Верховного Народного Суда КНР, можно предположить суще-

\footnotetext{
${ }^{6}$ Ануфриева Л. П., Бекямев Д. К., Бекяшев К. А. и др. Международное публичное право: учебник / отв.ред. К.А. Бекяшев. - 3-е изд., перераб. и доп. М.: ТК Велби, Изд-во Проспект, 2004. 928 с.

${ }^{7}$ Chen Weizuo. The necessity of Codification a China's private international law and arguments for a statute on the Application of laws as the legislative model. URL: http://asiansil.web.fc2. com/A-4/ chen_weizuo.pdf.

${ }^{8}$ Huang Jin and Du Huanfang. Chinese judicial practice in Private in 2001. Response of the Supreme People's Court to Certain Questions Concerning the Application of the Foreign Economic Contract Law of 19 October 1987. URL: www.lawinfochina.com (дата обращения 15.06.2014).

${ }^{9}$ Rules of the Supreme People's Court on the Relevant Issues concerning the Application of Law in Hearing Foreign-Related Contractual Dispute Cases in Civil and Commercial Matters of 23 July 2007. URL: www. lawinfochina.com (дата обращения 15.06.2014).
} 


\section{Право и политика $8(176) \cdot 2014$}

ствование в Китае тенденции непризнания обратной отсылки. Соответствующее сформулированное в праве КНР правило распространялось только на разрешение споров, вытекающих из частных договорных отношений с иностранным элементом, что согласуется с соответствующими положениями международного права ${ }^{10}$.

Тем не менее, в судебной практике встречались примеры, когда судья принимал обратную отсылку. В одном из них стороны спора в качестве применимого права выбрали право Китая, коллизионные нормы которого отсылали к иностранному праву, но судом были применены нормы иностранного права (закон страны флага судна) ${ }^{11}$.

Тенденция непризнания обратной отсылки и применение материального права иностранного государства в КНР нашли логичное закрепление в Законе от 28 октября 2010 г. В соответствии со ст. 9 иностранные законы, применяемые к гражданским отношениям с иностранным элементом, не включают законы этих государств о применении права, то есть законы, содержащие коллизионные нормы.

Проблема применения права с множественностью правовых систем была решена традиционным для КНР способом Верховным Народным Судом КНР. В Комментарии по некоторым вопросам, относящимся к применению Основных принципов (ст. 192), была установлена норма, согласно которой, в том случае, если в соответствии с коллизионными нормами китайского права должно быть применено право страны с множественностью правовых систем, применимое право должно быть применено в соответствии с коллизионными нормами такого государства. Если же государство не имеет таких норм, применяются нормы той правовой системы, которая наиболее тесно связана с гражданским правоотношением.

Эта тенденция нашла отражение и в ст. 5 Правил Верховного Народного Суда КНР от 23 июля 2007 г. В

\footnotetext{
${ }^{10}$ Гаагская конвенция о праве, применимом к договорам международной купли-продажи товаров 1986 г. (ст. 15) // Розенберг М.Г. Контракт международной купли-продажи. Современная практика заключения. Разрешение споров. М.: Международный центр финансово-экономического развития, 1996. С. 209-220; Римская конвенция о праве, применимом к договорным обязательствам (Convention on the Law Applicable to Contractual Obligations) 1980 г. (ст. 15) // Treaty Series. Volume 1605. - New York: United Nations, 1997. Р. 59 -156; Типовой закон ЮНСИТРАЛ о международном коммерческом арбитраже 1985 г. (ст. 28) // Официальный сайт OOH. URL: http://www. un.org/ru/documents/charter/chapter9.shtml (дата обращения 10.06.2014).

${ }^{11}$ Qingjiang Kong, Hu Minfei. The Chinese practice of private international law // Melbourne journal of International law. - 2002. - Vol. 3. URL: http:// article.chinalawinfo.com/article_print.asp? articleid $=54197$
}

этих правилах было закреплено, что суды при выборе применимого права к разрешению спора должны выбрать «страну или регион», имеющие наибольшую тесную связь с договором. Тем самым было установлено правило определения системы права иностранного государства, подлежащей применению по правилу Proper Law (право страны, с которой договор наиболее тесно связан).

Согласно ст. 6 Закона от 28 октября 2010 г. если различные регионы иностранных государств имеют разные действующие законы, то применяются те, которые имеют наибольшую связь с гражданскими отношениями с иностранным элементом. Таким образом, в законе закреплена сложившаяся тенденция применения права государств с множественностью правовых систем на основе Proper Law. Тем не менее, формулировка статьи нового закона позволяет определенно утверждать, что в праве КНР разрешена только проблема, связанная с выбором права государств, имеющих интерлокальную множественность. И эта статья не используется для определения применимой правовой системы стран с интерперсональной множественностью правовых систем.

В двух последних рассмотренных случаях формирование правовой традиции началось с формулировки Верховным Народным Судом КНР соответствующих норм. При этом уже существовал закон, в котором были закреплены нормы, регулирующие международные частные отношения. Тем не менее, изменения в закон не были внесены, а нормотворчество в этой области осуществил Верховный народный суд КНР. Сделать это было проще и быстрее. Положительным в таком нормотворчестве Верховного народного суда КНР можно считать то, что оно способствует единообразному применению норм на территории КНР, восполнению пробелов в правовом регулировании законодательства и накоплению опыта правового регулирования, который позже находит воплощение в законах этой страны. Установленными Высшим народным судом КНР нормами суды всех инстанций руководствовались на протяжении более двадцати лет. Думается, что этого времени достаточно для формирования модели мышления и поведения и на ее основе соответствующей правовой традиции.

Поскольку право КНР в середине 80-х годов начало допускать применение на её территории права иностранного государства, то актуальной стала оговорка о публичном порядке, которая ограничивала его применение. Статья 150 Основных принципов устанавливала ограничение подобного применения. Не подлежало применению право иностранного государства в том случае, если такое применение нарушало общественные инте- 
ресы КНР. При этом понятие общественных интересов не было конкретизировано. Это означало, что в каждом конкретном случае суд должен определять, причинит ли вред применение иностранного права на территории Китая его общественным интересам или нет ${ }^{12}$. Вполне очевидно, что в соответствие с правом КНР применение иностранного права, противоречащего ее праву на ее территории, автоматически не рассматривалось как нарушение публичного порядка. Это подтверждалось и положениями Правил Верховного Народного Суда КНР от 23 июля 2007 г. (ст. 7) и нашло отражение в Законе от 28 октября 2010 г. В соответствии со ст. 5 последнего, «если применение иностранного права нанесёт ущерб общественным публичным интересам Китайской Народной Республики, право Китайской Народной Республики должно применяться». Тем не менее, необходимо отметить, что пока остаётся неясным, в каких случаях применяется оговорка о публичном порядке в Китае, т.к. не сложилась однообразная практика применения этого института ${ }^{13}$.

В рассматриваемом случае при формировании правовой традиции новым законом было осуществлено преемство не только правоприменительной практики, но и нормы закона.

Рассмотренные примеры формирования традиций являются типичными для КНР. Прежде всего, обращает внимание, связь между практикой и правовыми нормами. Предпочтение собственной практики очевидно. Первые нормы, регулирующие международные частные отношения, были не многочисленны и не охватывали весь объем таких отношений. При этом пробелы в правовом регулировании восполнялись Верховным народным судом КНР свойственными ему методами. В результате его деятельности формировалась правоприменительная практика на территории КНР. Параллельно с реализацией рассмотренных норм, формированием судебной практики в научной среде КНР проходили дискуссии о ее форме и содержании.

Роль Верховного народного суда КНР в нормотворчестве и восполнении пробелов в правовом регулировании является особенностью китайской правовой системы. Несмотря на то, что такая его деятельность не соответствует принципу разделения властей, она вно-

\footnotetext{
${ }^{12}$ Chinese judicial practice in private international law: $2006 / /$ Chinese Journal of International law. - 2009. - 6 November. URL: http://www. iolaw.org.cn/pdf/paper/2010/Chinese.

${ }^{13}$ Wolff Lutz-Christian. China's Private International Investment Law: One-Way Street into PRC Law? / Lutz-Christian Wolff// The American Journal of Comparative Law. Vol. 56. - 2008. - P. 1039-1073.
}

сит свой вклад в формирование в обществе стабильных отношений и правовых традиций. Можно сказать, что это проявление «судебной власти с китайской спецификой», как и «построение социализма с китайской спецификой» и создание одного государства с несколькими правовыми системами, относящимися к разным правовым семьям, является особенностью китайской практики, которую не всегда возможно использовать в практике других государств в силу менталитета общества.

Из анализа опыта КНР в формировании правовых традиций можно сделать следующие выводы, которые могут быть полезны и для России:

1) при формировании правовых традиций собственный опыт правовой деятельности наиболее ценен, чем опыт зарубежных стран, поскольку он обусловлен особенностями реальной ситуации, сложившейся в государстве, и менталитетом общества;

2) при использовании приемлемых для любого государства методов формирования правовых традиций можно выработать способы, подходящие для конкретного социума с учетом зарубежного опыта;

3) формирование рациональных стереотипов и традиций возможно на основе последовательной практики реализации правовых норм, а не в результате изменения содержания правовых норм с целью поиска нормы, которая смогла бы достичь таких целей.

Очевидно, что на протяжении времени получения опыта, в результате которого может быть сформирован соответствующая правовая традиция, правовая деятельность должна быть последовательно направлена на ее формирование. В этом смысле последовательная правовая деятельность с определенной целью выступает как способ образования новых стереотипов и традиций. Правовые традиции могут быть сформированы следующими способами: «от юридической практики к норме права», «от лаконичной нормы права к развернутой через юридическую практику». При этом последовательность правовой деятельности может выражаться в следующем:

1) в обусловленности разработки новых, изменения существующих законодательных актов в соответствие с объективной необходимостью и потребностями общества, имеющими перспективу правового регулирования. Формирование традиций, а в дальнейшем правовых обычаев возможно только в том случае, если рациональное право разумно обоснованно и целесообразно для общества (становится для него рациональным);

2) в принятии норм, не противоречащих нормам морали, которые являются одной из форм общественного 


\section{Право и политика $8(176) \cdot 2014$}

сознания и мощным регулятором социальных отношений. Они складываются на протяжении длительного периода времени под воздействием множества объективных факторов. Это обусловливает их устойчивость. Соответствие правовых норм нормам морали позволяет быстрее сформироваться правовым стереотипам и традициям. Принятие норм права, противоречащих им, вызывает сопротивление со стороны общества, в том числе и в форме агрессии, что может помешать возникновению нового правового стереотипа, а затем и традиции. Тем не менее, необходимо признать, что иногда нормы права направлены на разрушение некоторых моральных стереотипов. В таких случаях необходимо проявление политической воли государства, а также осуществление правовой политики, направленной на формирование толерантности к таким случаям;

3) в принятии последовательных в своем содержании правовых норм, введенных в действие в разное время. Частое изменение содержания правовых норм не способствует формированию соответствующей модели определенного мышления и поведения из-за недостатка времени для этого, тем не менее, способствует разрушению старой;

4) в создании согласованно-направленных в своем воздействии на общество норм права, закрепленных в разных источниках;

5) в формировании практики правоприменения, соответствующей идее и содержанию правовых норм, поскольку она обладает регулятивным свойством, так же как и право. Согласованные функции права и практики его применения обеспечивают эффективность правовых норм, формирования традиций;

6) в осуществлении последовательной соответствующей правоприменительной практики. Объективно необоснованное изменение правоприменительной практики, так же как и изменение содержания правовых норм может привести к разрушению старых и стать препятствием для развития новых правовых традиций.

\section{Библиография:}

1. Конфуций. Лунь юй / Конфуций // Confucius Pablishing Co. Ltd. URL: http://www.confucius.org/ lunyu/rd0413.htm (дата обращения 20.03.2013).

2. Wang Hui. A review of China's private international law during the 30 year period of reform and opening up // Asian Law Institute Working Paper. - № 2. - May 2009. - P.3.

3. Huang Jin and Du Huanfang. Chinese judicial practice in Private in $2001 / /$ Chinese Journal of International Law. - 2003. - № 2(1). - C.387 - 416.
4. Huang Jin and Du Huanfang. Chinese judicial practice in Private in 2002 // Chinese Journal of International Law. - 2005. - № 4 (2). - C.647 - 676.

5. Huang Jin and Du Huanfang. Chinese judicial practice in Private international law: 2003 // Chinese Journal of International Law. - 2008. - Vol.7. - № 1. URL: http:// chinesejil. oxfordjournals

6. Private international law in the Chinese judicial practice in 2006. URL: http://www.iolaw.org.cn/pdf/ paper/2010/Chinese \%20Judicial\%20Practice\%20in \%20Privat\%20International\%20Law\%202006.pdf

7. Chen Weizuo. The necessity of Codification a China's private international law and arguments for a statute on the Application of laws as the legislative model. URL: http://asiansil.web.fc2. com/A-4/chen_weizuo.pdf.

8. Huang Jin and Du Huanfang. Chinese judicial practice in Private in 2001. Response of the Supreme People's Court to Certain Questions Concerning the Application of the Foreign Economic Contract Law of 19 October 1987. URL: www.lawinfochina.com.

9. Rules of the Supreme People's Court on the Relevant Issues concerning the Application of Law in Hearing Foreign-Related Contractual Dispute Cases in Civil and Commercial Matters of 23 July 2007. URL: www. lawinfochina.com.

10. Chinese judicial practice in private international law: 2006 // Chinese Journal of International law. - 2009. - 6 November. URL: http:/www.iolaw.org.cn/pdf/ paper/2010/Chinese

11. Wolff Lutz-Christian. China's Private International Investment Law: One-Way Street into PRC Law? / Lutz-Christian Wolff // The American Journal of Comparative Law. Vol. 56. - 2008. - Р. 1039-1073.

12. Ткаченко С.В. Содержание рецепции права // NB: Вопросы права и политики. - 2013. - № 6. - C.42-62. DOI: 10.7256/2305-9699.2013.6.818. URL: http://enotabene.ru/1r/article_818.html

13. Лазота Л.А. Общая картина структуры источников торгового права стран БРИКС // NB: Вопросы права и политики. - 2013. - № 10. - C.1-11. DOI: 10.7256/2305-9699.2013.10.7400. URL: http://enotabene.ru/lr/article_7400.html

14. ВанШ.Л., Войскунский А.Е. Теоретико-эмпирическое исследование становления психологии Интернета в Китае на материале проблемы зависимости от Интернета // NB: Психология и психотехника. -2013. - № 4. - C.155-237. DOI: 10.7256/2306-0425.2013.4.738. URL: http://e-notabene.ru/psp/article_738.html

15. Верченко А.Л. Синьхайская революция в Китае: новые подходы к старым традициям // NB: 
Исторические исследования. - 2012. - № 2. - С.191235. DOI: $10.7256 / 2306-420 X .2012 .2 .374$. URL: http://e-notabene.ru/hr/article_374.html

16. Кананыкина Е.С. Источники права об образовании в социалистической системе Китая // NB: Проблемы общества и политики. - 2013. - № 6. C.137-158. DOI: 10.7256/2306-0158.2013.6.456. URL: http://e-notabene.ru/pr/article_456.html

17. Бородин Е.А.. Современные политические реалии Центральной Азии: Россия, Китай и Кыргызстан // Политика и Общество. - 2014. - № 1. - С. 104-107. DOI: $10.7256 / 1812-8696.2014 .1 .9997$

18. Разумов Ю.А. Некоторые конституционноправовоые особенности реализации норм международного права в военной сфере в зарубежных странах // NB: Международное право. - 2013. - № 1. - C.171-183. DOI: 10.7256/23069899.2013.1.684. URL: http://e-notabene.ru/wl/ article_684.html

19. Рубец М.В.. Когнитивные особенности китайской культуры и языка // Психология и Психотехника. - 2013. - № 11. - C. 104-107. DOI: 10.7256/20708955.2013.11.10149

20. Кананыкина Е.С.. Юридические формы источников права об образовании в социалистической системе Китайской Народной Республики // Политика и Общество. - 2013. - № 9. - С. 104-107. DOI: 10.7256/1812-8696.2013.9.2487

21. И.М. Афанасьева. Интегрированная модель политического взаимовлияния в континентальном Китае и административном районе Сянган // Политика и Общество. - 2013. - № 3. - С. 104-107. DOI: $10.7256 / 1812-8696.2013 .03 .12$

22. Е. В. Соловьёва. Стратегическое партнерство России и Китая как фактор культурного взаимодействия в современных политических условиях // Политика и Общество. - 2012. - № 1. - С. 104-107.

23. А. Л. Верченко. Синьхайская революция: некоторые аспекты обновления китайского общества // Исторический журнал: научные исследования. - 2011. - № 5. - C. 104-107

\section{References (transliteration):}

1. Konfutsii. Lun' yui / Konfutsii // Confucius Pablishing Co. Ltd. URL: http://www.confucius.org/lunyu/rd0413. htm (data obrashcheniya 20.03.2013).

2. Wang Hui. A review of China's private international law during the 30 year period of reform and opening up // Asian Law Institute Working Paper. - № 2. - May 2009. - R.3.

3. Huang Jin and Du Huanfang. Chinese judicial practice in Private in $2001 / /$ Chinese Journal of International Law. - 2003. - № 2(1). - S.387 - 416.

4. Huang Jin and Du Huanfang. Chinese judicial practice in Private in 2002 // Chinese Journal of International Law. - 2005. - № 4 (2). - S.647 - 676.

5. Huang Jin and Du Huanfang. Chinese judicial practice in Private international law: 2003 // Chinese Journal of International Law. - 2008. - Vol.7. - № 1. URL: http:// chinesejil. oxfordjournals

6. Chen Weizuo. The necessity of Codification a China's private international law and arguments for a statute on the Application of laws as the legislative model. URL: http://asiansil.web.fc2. com/A-4/chen_weizuo.pdf.

7. Huang Jin and Du Huanfang. Chinese judicial practice in Private in 2001. Response of the Supreme People's Court to Certain Questions Concerning the Application of the Foreign Economic Contract Law of 19 October 1987. URL: www.lawinfochina.com.

8. Wolff Lutz-Christian. China's Private International Investment Law: One-Way Street into PRC Law? / Lutz-Christian Wolff // The American Journal of Comparative Law. Vol. 56. - 2008. - P. 1039-1073.

9. Tkachenko S.V. Soderzhanie retseptsii prava // NB: Voprosy prava i politiki. - 2013. - № 6. - S.42-62. DOI: 10.7256/2305-9699.2013.6.818. URL: http://e-notabene. $\mathrm{ru} / \mathrm{lr} / \mathrm{article} 818 . \mathrm{html}$

10. Lazota L.A. Obshchaya kartina struktury istochnikov torgovogo prava stran BRIKS // NB: Voprosy prava i politiki. - 2013. - № 10. - S.1-11. DOI: 10.7256/23059699.2013.10.7400. URL: http://e-notabene.ru/lr/ article_7400.html

11. Van Sh.L., Voiskunskii A.E. Teoretiko-empiricheskoe issledovanie stanovleniya psikhologii Interneta $\mathrm{v}$ Kitae na materiale problemy zavisimosti ot Interneta // NB: Psikhologiya i psikhotekhnika. - 2013. - № 4.S.155-237. DOI: 10.7256/2306-0425.2013.4.738. URL: http://e-notabene.ru/psp/article_738.html

12. Verchenko A.L. Sin'khaiskaya revolyutsiya v Kitae: novye podkhody $\mathrm{k}$ starym traditsiyam // NB: Istoricheskie issledovaniya. - 2012. - № 2. - S.191-235. DOI: 10.7256/2306-420X.2012.2.374. URL: http://enotabene.ru/hr/article_374.html

13. Kananykina E.S. Istochniki prava ob obrazovanii $\mathrm{v}$ sotsialisticheskoi sisteme Kitaya // NB: Problemy obshchestva i politiki. - 2013. - № 6. - S.137-158. DOI: 10.7256/2306-0158.2013.6.456. URL: http://e-notabene. $\mathrm{ru} / \mathrm{pr} /$ article_456.html 
DOI: $10.7256 / 1811-9018.2014 .8 .12565$

При цитировании этой статьи сноска на dоі обязательна

\section{Право и политика 8 (176) • 2014}

14. Borodin E.A.. Sovremennye politicheskie realii Tsentral'noi Azii: Rossiya, Kitai i Kyrgyzstan // Politika i Obshchestvo. - 2014. - № 1. - S. 104-107. DOI: 10.7256/1812-8696.2014.1.9997

15. Razumov Yu.A. Nekotorye konstitutsionno-pravovoye osobennosti realizatsii norm mezhdunarodnogo prava v voennoi sfere v zarubezhnykh stranakh // NB: Mezhdunarodnoe pravo. - 2013. - № 1. - S.171-183. DOI: 10.7256/2306-9899.2013.1.684. URL: http://enotabene.ru/wl/article_684.html

16. 1Rubets M.V.. Kognitivnye osobennosti kitaiskoi kul'tury i yazyka // Psikhologiya i Psikhotekhnika. - 2013. - № 11. - S. 104-107. DOI: 10.7256/2070-8955.2013.11.10149

17. Kananykina E.S.. Yuridicheskie formy istochnikov prava ob obrazovanii v sotsialisticheskoi sisteme Kitaiskoi
Narodnoi Respubliki // Politika i Obshchestvo. - 2013. № 9. - S. 104-107. DOI: 10.7256/1812-8696.2013.9.2487

18. I.M. Afanas'eva. Integrirovannaya model' politicheskogo vzaimovliyaniya v kontinental'nom Kitae i administrativnom raione Syangan // Politika i Obshchestvo. - 2013. - № 3. - S. 104-107. DOI: 10.7256/18128696.2013.03.12

19. E. V. Solov'eva. Strategicheskoe partnerstvo Rossii i Kitaya kak faktor kul'turnogo vzaimodeistviya $\mathrm{v}$ sovremennykh politicheskikh usloviyakh // Politika i Obshchestvo. - 2012. - № 1. - S. 104-107.

20. A. L. Verchenko. Sin'khaiskaya revolyutsiya: nekotorye aspekty obnovleniya kitaiskogo obshchestva // Istoricheskii zhurnal: nauchnye issledovaniya. - 2011. - № 5. - S. 104-107 